\title{
A MODEL OF ICICLE GROWTH
}

\author{
By LASSE MAKKONEN
}

(Laboratory of Structural Engineering, Technical Research Centre of Finland, 02150 Espoo, Finland)

ABSTRACT. A theory of icicle growth is presented. It is shown that icicles elongate as hollow tubes of ice with liquid water trapped inside the tip. A time-dependent computer model based on the theory shows that the growth of an icicle is a complicated process, which is very sensitive to the atmospheric conditions and water flux. The shape and weight of icicles predicted by the model agree well with laboratory data.

\section{INTRODUCTION}

In cold areas of the world icicles are commonly seen. Wherever cold water flows from an overhang at freezing temperatures, icicles will form. They hang from the roofs of buildings, ledges, and tree branches after periods of snow melt or freezing rain, and as a result of water seepages.

Icicles are nice to look at, and they are useful in that they can be used as a guide to the quality and movement of ground water (Reesman, 1973), and that their formation on buildings reveals thermal leaks. It is not always recognized that icicles are also a problem. They may fall on people and cause serious injuries. When hanging from the roof of a railway tunnel they may penetrate the windshield of a passing engine (Shinojima, 1973). Icicles also contribute to ice loads on trees and structures, such as power lines, masts, and ships. Formation of icicles on insulators of a power line may also cause flash-overs. Estimation of icicle formation is, therefore, necessary in many engineering applications.

The general characteristics and crystal structure of icicles have been studied by Hatakeyama and Nemoto (1958), Lenggenhager (1978), Knight (1968, 1980), Geer (1981), Burt (1982), and Maeno and Takahashi (1984[b]). Suggestions for the growth mechanisms of icicles have also been made (Hatakeyama and Nemoto, 1958; Laudise and Barns, 1979), but the only quantitative study of icicle growth is that by Maeno and Takahashi (1958[a]), in which empirical relationships between icicle growth and environmental conditions were obtained by laboratory tests. In the present paper, a quantitative theory of icicle growth is developed. The theory can be used in simulating the evolution of the shape and mass of icicles.

\section{THE GROWTH MECHANISMS}

When there is a source of water at the root of the icicle, a liquid film forms on the icicle surface and flows towards the tip due to gravity or wind drag. Water spreads effectively on an icicle surface due to the high surface energy of ice. Therefore, the liquid water covers uniformally the entire icicle surface, unless the flux of water is extremely small. The thickness of the liquid film on the icicle surface during its growth is typically 40-100 $\mu \mathrm{m}$ (Maeno and Takahashi, 1984[a]).

While water flows down along the icicle surface, a part of it freezes but, if the water supply is sufficient, a pendant drop forms at the tip of the icicle. Only then can the icicle grow in length. The pendant drop grows until it reaches a certain size and then falls, whereafter another drop starts to grow. The shape of the pendant drop changes during its growth and its mean shape can be approximated by a hemisphere. Measurements under calm conditions show that the diameter of the pendant drop, and the diameter of the tip of the icicle, is $4.8-5.0 \mathrm{~mm}$ regardless of growth conditions (Maeno and Takahashi, 1984[a]).

When an icicle grows, the latent heat of fusion released in the freezing of ice beneath the water film must be removed from the ice/water interface. The rate of heat loss from the surface to the environment, therefore, controls the growth rate of ice. The situation is analogous to "wet growth" of hailstones and spray ice.

The heat loss from the surface to the air is mainly by thermal convection and by evaporation. Outgoing radiation is small and heat conduction to the interior of the icicle is negligible. The water film on the surface is supercooled only by less than $0.02^{\circ} \mathrm{C}$ everywhere on the icicle walls (Hillig and Turnbull, 1956), so that changes in the film temperature do not significantly contribute to the heat balance. The pendant drop, on the other hand, may cool more significantly and may therefore release heat to the tip of the icicle.

Icicles are long spikes of ice. In order to form, their growth in length must be typically $10-30$ times faster than their growth in width. When considering a cross-section of an icicle, there are two surfaces growing horizontally and one growing vertically. Therefore, the elongation rate of the tip of an icicle is typically $20-60$ times the radial growth rate of the walls. As discussed above, the local ice-growth rate is proportional to the local heat loss from the icicle surface. Consequently, the heat loss from the tip of the icicle should be $20-60$ times the heat loss from the walls. As cooling of the pendant drops releases heat to the tip of the icicle and thereby reduces its growth rate, it would have to be the convective and evaporative heat transfer to the air that is $20-60$ times higher at the tip than on the walls. Any review of the literature on heat transfer from cylindrical bodies reveals that this is not possible; the vertical and horizontal heat-transfer rates from a cylindrical body are of the same order of magnitude. Yet, we know that icicles do grow much faster in length than in width.

There is only one plausible explanation of the abovementioned paradox. As the observed vertical growth rate of an icicle is much higher than one based on heat loss, it must only be the vertical dimension of the tip of the icicle that is growing fast, not the mass of ice. In other words, the tip of the icicle must grow vertically as a thin cover of ice enclosing unfrozen water. By this mechanism, the surface area from which the heat loss takes place, i.e. the hemispherical surface of the pendant drop, is much bigger than the surface area of ice that is growing vertically and releasing latent heat of fusion. The situation is shown schematically in Figure 1.

The proposed growth mechanism is consistent with the qualitative description by Maeno and Takahashi (1984[a]) and with observations that icicles grow as thin-walled tubes with liquid water trapped inside the icicle (Geer, 1981). The author has also made observations on growing icicles in the laboratory and in Nature, and found that liquid water extends several centimeters up into the interior of a growing icicle. In some cases, a wooden toothpick or a similar object can be pushed into the icicle from the tip upwards almost as far as to the root of the icicle. In agreement with the theoretical concept, the observations showed that the liquid tube inside the icicle has a constant diameter, which is equal to the diameter of the icicle at the tip. 


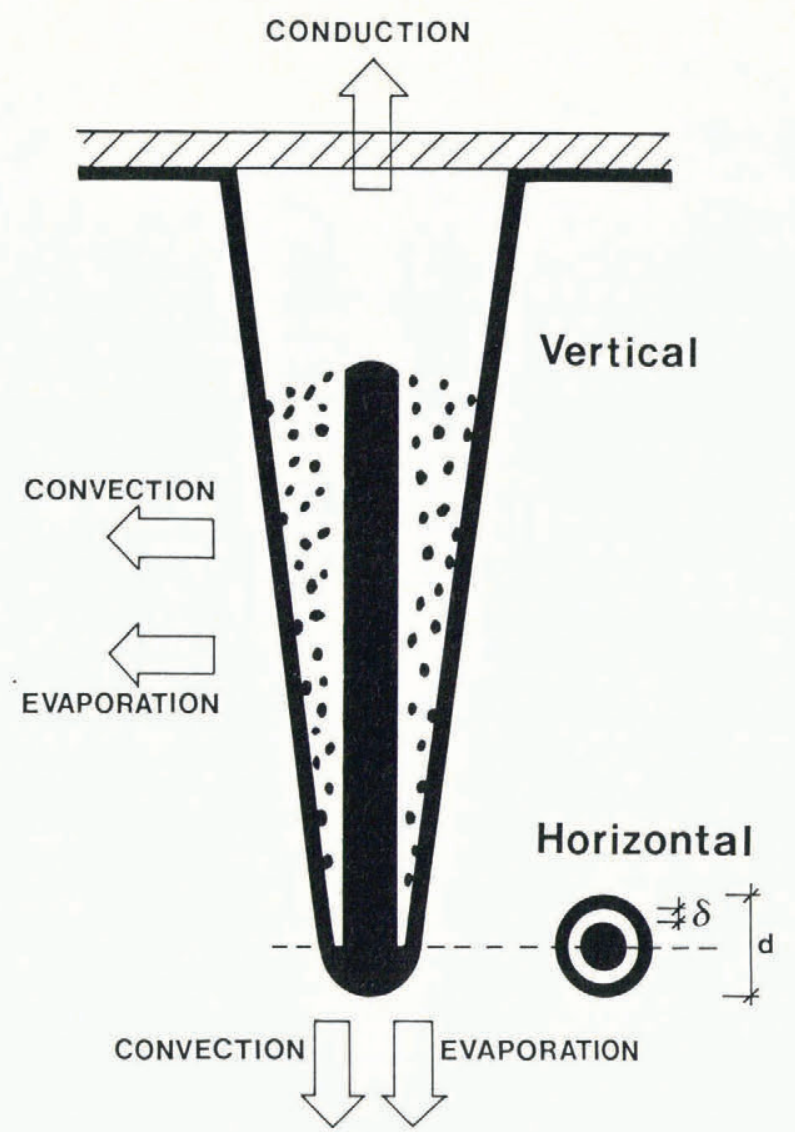

Fig. 1. Schematic cross-sections of a growing icicle. Dark is liquid water and white is ice. Dimensions are exaggerated.

It is noteworthy that the conclusion of the above analysis is not only that icicles can grow vertically as thin tubes of ice enclosing liquid water but also that they always must grow that way. An icicle that has a frozen interior at the tip is, therefore, not growing in length, i.e. the tip is dry or the icicle is melting.

The liquid water in the interior of an icicle cannot be frozen by processes that transfer heat downwards or horizontally, because there can be no temperature gradients in these directions, as the temperature of the walls and the tip of the icicle is at the freezing temperature. Therefore, the only mechanism by which the entrapped liquid water can be subsequently frozen is heat conduction upwards through the root of the icicle. By this process, the liquid water inside the icicle freezes slowly from the root downwards (Fig. 1). The downward penetration of the freezing front inside the icicle is much slower than the typical vertical growth rate of the tip of the icicle, leaving the interior of the tip of the growing icicle liquid. The conduction through the root of the icicle does not affect the icicle growth rate, as it does not contribute to the heat balance of the icicle surface. Only conduction determines how fast the interior of the icicle changes from liquid to solid.

Once the thin cover of ice at the tip of an icicle has grown vertically, it also starts to grow horizontally outwards due to heat loss to the air at the icicle walls. The icicle then grows in width. As the ice on the walls grows beneath a supercooled water film, the ice/water interface assumes a dendritic sub-structure (cf. Harrison and Tiller, 1963). This results in the growth of spongy ice, i.e. ice with liquid water entrapped in the ice matrix (Knight, 1968; Makkonen, 1987). As for the liquid water in the interior, complete freezing of the spongy walls is possible only by slow conduction upwards through the root of the icicle, or by surface heat transfer once the ice growth on the walls has ended. Therefore, during the growth of an icicle, its walls consist of spongy ice, except possibly close to the root of the icicle (Fig. 1).

\section{MODEL DETAILS}

\subsection{Growth in length}

For heat-transfer calculations, it is assumed that, averaged over its life-time, the pendant drop, i.e. the tip of the icicle, is hemispherical. Based on the data by Maeno and Takahashi (1984[a]), a droplet diameter, $d$, of $4.9 \mathrm{~mm}$ is adopted in the model.

The heat balance of the surface of the hemispherical tip of the icicle includes convective and evaporative cooling terms, $q_{\text {conv }}$ and $q_{\text {evap }}$, a radiation term, $q_{\text {rad }}$, and terms related to temperature changes of the pendant drops, $q_{\text {drip }}$, and to latent heat released in the freezing process, $q_{\text {freez }}$ :

$$
q_{\text {conv }}+q_{\text {evap }}+q_{\text {rad }}=q_{\text {drip }}+q_{\text {freez }} .
$$

The terms of the heat balance can be parameterized as follows (cf. Makkonen, 1984).

The convective heat transfer is

$$
q_{\text {conv }}=h\left(0^{\circ} \mathrm{C}-t_{\mathrm{a}}\right)
$$

where $h$ is the convective heat-transfer coefficient, and $t_{\mathrm{a}}$ is the air temperature. Calculation of the heat-transfer coefficient for the tip of the icicle is explained in Appendix A.

Evaporative heat transfer is

$$
q_{\text {evap }}=h \frac{0.622 L_{\mathrm{e}}}{c_{\mathrm{p}} p_{\mathrm{a}}}\left(e\left(0^{\circ} \mathrm{C}\right)-\operatorname{Re}\left(t_{\mathrm{a}}\right)\right)
$$

where $L_{\mathrm{e}}$ is the latent heat of evaporation at $0^{\circ} \mathrm{C}, e\left(0^{\circ} \mathrm{C}\right)$ and $e\left(t_{\mathrm{a}}\right)$ are the saturation water-vapour pressures over water at $0^{\circ} \mathrm{C}$ and at $t_{a}$, respectively, $R$ is the relative humidity, $c_{\mathrm{p}}$ is the specific heat of water, and $p_{\mathrm{a}}$ is the air pressure. Long-wave radiation from the surface can be parameterized as

$$
q_{\mathrm{rad}}=\sigma a\left(0^{\circ} \mathrm{C}-t_{\mathrm{a}}\right)
$$

where $\sigma$ is the Stefan-Boltzmann constant and $a=8.1 \times$ $10^{7} K^{3}$. In Equation (4), it is assumed that the emissivities of the surface and the environment are both unity. The Sun's radiation is excluded from the model, as it is generally unknown, and non-existent under laboratory conditions.

There is a fourth term in the heat balance of the tip of the icicle, which results from the fact that the pendant drop at the tip is generated from run-off water at wall temperature, but leaves the tip of the icicle at a slightly lower temperature. The flux of heat due to drop cooling, is

$$
Q_{\text {drip }}=c_{\mathrm{w}} W_{\mathrm{d}} \Delta T
$$

where $c_{\mathrm{w}}$ is the specific heat of water, $W_{\mathrm{d}}$ is the mass flux of water to the tip, and $\Delta T$ is the temperature change of the pendant drops from the wall temperature to their temperature when they fall. In accordance with Equations (2)-(4), we can formulate the heat flux released due to drop cooling in terms of heat transfer per unit area of the surface. The mean surface area of the hemispherical pendant drop is equal to $\pi d^{2} / 2$. Hence, it follows from Equation (5) that the heat flux due to drop cooling per unit surface area of the tip of the icicle is

$$
q_{\text {drip }}=\frac{2 c_{\mathrm{w}} W_{\mathrm{d}} \Delta T}{\pi d^{2}} .
$$

The mass flux $W_{\mathrm{d}}$ depends on the water flux to the root of the icicle $W_{0}$ (which is an input for the model) and the loss of water on the icicle walls due to freezing and evaporation. When the mean diameter of the icicle is denoted as $D$, the length of the icicle as $L$, and the evaporation is parameterized as in Equation (3), the drip flux becomes

$$
W_{\mathrm{d}}=W_{0}-\pi L D\left[\rho_{\mathrm{a}} \frac{1}{2} \frac{\mathrm{d} D}{\mathrm{~d} t}+h \frac{0.622}{c_{\mathrm{p}} p_{\mathrm{a}}}\left(e\left(0^{\circ} \mathrm{C}\right)-\operatorname{Re}\left(t_{\mathrm{a}}\right)\right)\right]
$$


where $\rho_{\mathrm{a}}$ is the density of the icicle walls (cf. Equation (20)).

The crystal orientation on the icicle walls is such that the $c$-axis is perpendicular to the growth direction (Knight, 1968; Laudise and Barns, 1979). The same is probably true at the tip of the icicle (Maeno and Takahashi, 1984[a]). In such a situation, the ice-growth rate, $v$, (in $\mathrm{cm} / \mathrm{s}$ ) is related to the degree of supercooling close to the ice/water interface $T_{\mathrm{sp}}$ (in ${ }^{\circ} \mathrm{C}$ ) by (Hillig and Turnbull, 1956)

$$
v=0.16\left(T_{\mathrm{sp}}\right)^{1.7}
$$

Assuming that the thin liquid layer on the icicle wall is well mixed, the temperature, $T_{\mathrm{i}}$, of the run-off water entering the tip of the icicle can therefore be estimated as

$$
T_{\mathrm{i}}=-\left[\frac{\frac{1}{2} \mathrm{~d} D / \mathrm{d} t}{0.16}\right]^{0.588} .
$$

Assuming further that the convection within the pendant drop is sufficiently effective to remove large temperature gradients, the temperature of the pendant drop in the mean, $T_{\mathrm{M}}$, is

$$
T_{\mathrm{M}}=-\left[\frac{\mathrm{d} L / \mathrm{d} t}{0.16}\right]^{0.588} .
$$

It follows from Equations (9) and (10) that the temperature change, $\Delta T=T_{\mathrm{i}}-T_{\mathrm{M}}$, of water forming the pendant drop can be approximated as

$$
\Delta T=5.88\left[\frac{\mathrm{d} L}{\mathrm{~d} t}-\frac{1}{2} \frac{\mathrm{d} D}{\mathrm{~d} t}\right]^{0.588}
$$

where $\mathrm{d} D / \mathrm{d} t$ and $\mathrm{d} L / \mathrm{d} t$ are in $\mathrm{cm} / \mathrm{s}$.

The final term in the heat balance of the icicle surface is the latent heat of fusion released in the freezing process. For the tip of the icicle this is

$$
Q_{\text {freez }}=L_{\mathrm{f}} \frac{\mathrm{d} M}{\mathrm{~d} t}
$$

where $\mathrm{d} M / \mathrm{d} t$ is the mass growth rate of ice at the tip. As discussed in section 2, an icicle grows vertically as a thinwalled tube. The inner diameter of this tube is about the same as that of the pendant drop, $d$, and the wall at the tip has a finite thickness $\delta$. It follows from simple geometrical considerations that the surface area of the vertically growing ice, $A_{\mathrm{i}}$, is

$$
A_{\mathrm{i}}=\pi \delta(d-\delta) \text {. }
$$

It follows from Equations (12) and (13) that

$$
Q_{\text {freez }}=L_{\mathrm{f}} \rho_{\mathrm{i}} \pi \delta(d-\delta) \frac{\mathrm{d} L}{\mathrm{~d} t}
$$

where $\rho_{i}$ is ice density and $L$ is the length of the icicle. Hence, heat flux due to latent heat of fusion per unit surface area of the hemispherical tip of the icicle is

$$
q_{\mathrm{freez}}=\frac{2 L_{\mathrm{f}} \rho_{\mathrm{i}} \delta(d-\delta)}{d^{2}} \frac{\mathrm{d} L}{\mathrm{~d} t} .
$$

Using the parameterizations in Equations (2), (3), (4), (6), and (15) and Equations (7) and (11), the heat-balance Equation (1) reads

$$
\begin{aligned}
& -h t_{\mathrm{a}}+h \frac{0.622 L_{\mathrm{e}}}{c_{\mathrm{p}} p_{\mathrm{a}}}\left\{e\left(0^{\circ} \mathrm{C}\right)-\operatorname{Re}\left(t_{\mathrm{a}}\right)\right\}-\sigma a t_{\mathrm{a}} \\
& =\frac{3.74 c_{\mathrm{w}}}{d^{2}}\left[W_{0}-\pi L D\left[\rho_{\mathrm{a}} \frac{1}{2} \frac{\mathrm{d} D}{\mathrm{~d} t}+\right.\right.
\end{aligned}
$$

$$
\begin{aligned}
& \left.+h \frac{0.622}{c_{\mathrm{p}} p_{\mathrm{a}}}\left(e\left(0^{\circ} \mathrm{C}\right)-\operatorname{Re}\left(t_{\mathrm{a}}\right)\right)\right]\left[\frac{\mathrm{d} L}{\mathrm{~d} t}-\frac{1}{2} \frac{\mathrm{d} D}{\mathrm{~d} t}\right)^{0.588}+ \\
& +\frac{2 L_{\mathrm{f}} \rho_{\mathrm{i}} \delta(d-\delta)}{d^{2}} \frac{\mathrm{d} L}{\mathrm{~d} t} .
\end{aligned}
$$

The elongation rate of the icicle, $\mathrm{d} L / \mathrm{d} t$, can now be solved from Equation (16). In the model, Equation (16) is solved numerically and the necessary value of the growth rate of the icicle mean diameter, $\mathrm{d} D / \mathrm{d} t$, is for each timestep obtained as explained in section 3.2 .

Equation (16) includes the initial wall thickness, 8, of the tube-like ice that is growing vertically. In order to use the model for calculating icicle growth, an estimate of $\delta$ must, therefore, be made. The pendant drop is supercooled, resulting in dendritic growth. Suppose there were several dendrites growing downwards, one within the other. Then, one of them would be the outer one in contact with the flux of supercooled water running down the icicle wall into the pendant drop. It is obvious that the ability of this dendrite to transfer latent heat of fusion to the environment at its tip would be much better than that of the dendrites growing in the inner parts of the wall. The dendrite at the outer surface would, therefore, grow much faster than the other dendrites. A conclusion of this is that the thickness of the wall of the ice tube growing vertically is that of a single dendrite. According to Harrison and Tiller (1963), the width of the dendritic cells growing beneath supercooled water may depend on the growth conditions, but are in the range of $50-100 \mu \mathrm{m}$. As more precise estimates of $\delta$ are lacking, a value of $75 \mu \mathrm{m}$ is used for $\delta$ in the model.

\subsection{Growth in width}

For heat-transfer calculations of the icicle walls, the icicle is approximated by a circular cylinder. In the model, the diameter $D$ of the cylinder represents the mean diameter of the icicle. Thus, only one characteristic horizontal dimension is modelled. The mean diameter $D$ is not necessarily equal to the diameter at $L / 2$, as the exact shape of the icicle is not pre-defined.

The heat balance at the wall of the icicle is

$$
q_{\text {conv }}+q_{\text {evap }}+q_{\text {rad }}=q_{\text {freez }}
$$

Here it is assumed that the degree of supercooling of the water that comes to the root of the icicle is on average the same as that on the icicle walls, so that no term corresponding to $q_{\text {drip }}$ in section 3.1 is included in the heat balance.

The heat of fusion term $q_{\text {freez }}$ cannot be evaluated directly from the mass growth rate $\mathrm{d} M / \mathrm{d} t$ at the icicle wall As noted in section 2, an ice surface grown under a film of supercooled water assumes a dendritic growth morphology and traps unfrozen water. The liquid water trapped within the ice matrix does not release heat of fusion to the icing surface. Hence the term $q_{\text {freez }}$ becomes

$$
q_{\text {freez }}=\frac{1}{A} L_{\mathrm{f}}(1-\lambda) \frac{\mathrm{d} M}{\mathrm{~d} t}
$$

where $A$ is the surface area and $\lambda$ is the liquid fraction of the growing icicle surface. Makkonen (1987) has suggested that the liquid fraction $\lambda$ has a value of approximately 0.26 regardless of the growth conditions. Data by Lesins and others (1980) show particularly that $\lambda$ is independent of air temperature. The value of $\lambda=0.26$ is used for Equation (18) in the present model.

The radial growth rate of the icicle wall $\frac{1}{2} \mathrm{~d} D / \mathrm{d} t$ is related to the growth rate of mass by

$$
\frac{\mathrm{d} M}{\mathrm{~d} t}=\rho_{\mathrm{a}} A \frac{1}{2} \frac{\mathrm{d} D}{\mathrm{~d} t}
$$

where $\rho_{a}$ is the density of the icicle wall. Since the ice matrix includes liquid water, the wall density $\rho_{a}$ in Equations (19) and (17) is different from the density $\rho_{i}$ of pure ice. 


$$
\rho_{\mathrm{a}}=\lambda \rho_{\mathrm{w}}+(1-\lambda) \rho_{\mathrm{i}}
$$

where $\rho_{W}$ is the density of water.

Equations (18) and (19) result in the following equation for the term $q_{\text {freez }}$ in Equation (17)

$$
q_{\text {freez }}=\frac{1}{2} \rho_{\mathrm{a}} L_{\mathrm{f}}(1-\lambda) \frac{\mathrm{d} D}{\mathrm{~d} t} .
$$

For the heat-transfer terms on the left-hand side of Equation (17), the same parameterizations as for the tip of the icicle can be used, providing that the proper heattransfer coefficient $h$ is chosen. Determination of $h_{\mathrm{w}}$ for the icicle walls is given in Appendix B.

Inserting Equations (2)-(4) and (21) into Equation (17) and solving $\mathrm{d} D / \mathrm{d} t$ results in the following equation for the growth rate of the mean diameter of an icicle:

$$
\frac{\mathrm{d} D}{\mathrm{~d} t}=\frac{-h_{\mathrm{w}} t_{\mathrm{a}}+h_{\mathrm{w}} \frac{0.622 L_{\mathrm{e}}}{c_{\mathrm{p}} p_{\mathrm{a}}}\left\{e\left(0^{\circ} \mathrm{C}\right)-\operatorname{Re}\left(t_{\mathrm{a}}\right)\right\}-\sigma a t_{\mathrm{a}}}{\frac{1}{2} \rho_{\mathrm{a}} L_{\mathrm{f}}(1-\lambda)}
$$

Equation (22) is a simple equation in that it can be solved analytically. It should be noted, however, that the heat-transfer coefficient $h_{\mathrm{w}}$ depends on both the icicle diameter $D$ and icicle length $L$ (see Appendix B). Therefore, $\mathrm{d} D / \mathrm{d} t$ is time-dependent, and solving Equation (22) requires simultaneous solution for $L$.

\subsection{Features of the computer model}

The theory in sections 3.1 and 3.2 has been programmed into a micro-computer. The flow diagram of the computer model is shown in Figure 2.

The icicle growth is initiated by a single drop, and therefore the initial values of $L$ and $D$ are $L=d / 2$ and $D=d$. The model simulation proceeds at time steps of $2 \mathrm{~min}$.

For the first time step, no supercooling or loss of water on the walls is allowed and the growth rate in length is solved from Equation (16) by iteration. Then the growth rate in width is calculated from Equation (22) using the heat-transfer coefficient based on the initial icicle diameter $D=d$ and the new value of $L$. The time step is completed by calculating the loss of water on the walls and the resulting new drip rate from Equation (7) as well as the new diameter $D$. These values and $\mathrm{d} D / \mathrm{d} t$ are then used in Equation (16) in calculating the new $\mathrm{d} L / \mathrm{d} t$. This results in a new icicle length $L$, which is again used in Equations (B1) and (B4) in order to calculate $\mathrm{d} D / \mathrm{d} t$ for the next time step. The process goes on over the time period set by the user of the model.

A possible mode of icicle growth is such that all the available water is lost on the walls, no drip occurs and, therefore, there is no growth in length. The icicle diameter, however, grows as long as there is water supply to the root of the icicle. In this case, all the supply water, except the small amount that evaporates, freezes on the icicle. Therefore, the growth rate in width is obtained simply from Equation (7), noting that the drip rate $W_{d}=0$ when the tip of the icicle is dry.

The mass of the icicle is in many applications the most interesting output of the model. The mass, $M$, is calculated simply by

$$
M=\frac{\pi D^{2}}{4} \rho_{\mathrm{a}} L
$$

\section{RESULTS AND DISCUSSION}

Examples of icicle-growth simulations by the model are shown in Figures 3 and 4 . The results in Figure 3 demonstrate that the growth rate of icicle length decreases with water-supply rate, $W_{0}$, while the growth rate of icicle width is only slightly affected by $W_{0}$. The net result is that the mass of an icicle decreases with increasing water-supply rate, providing that the water supply is all the time

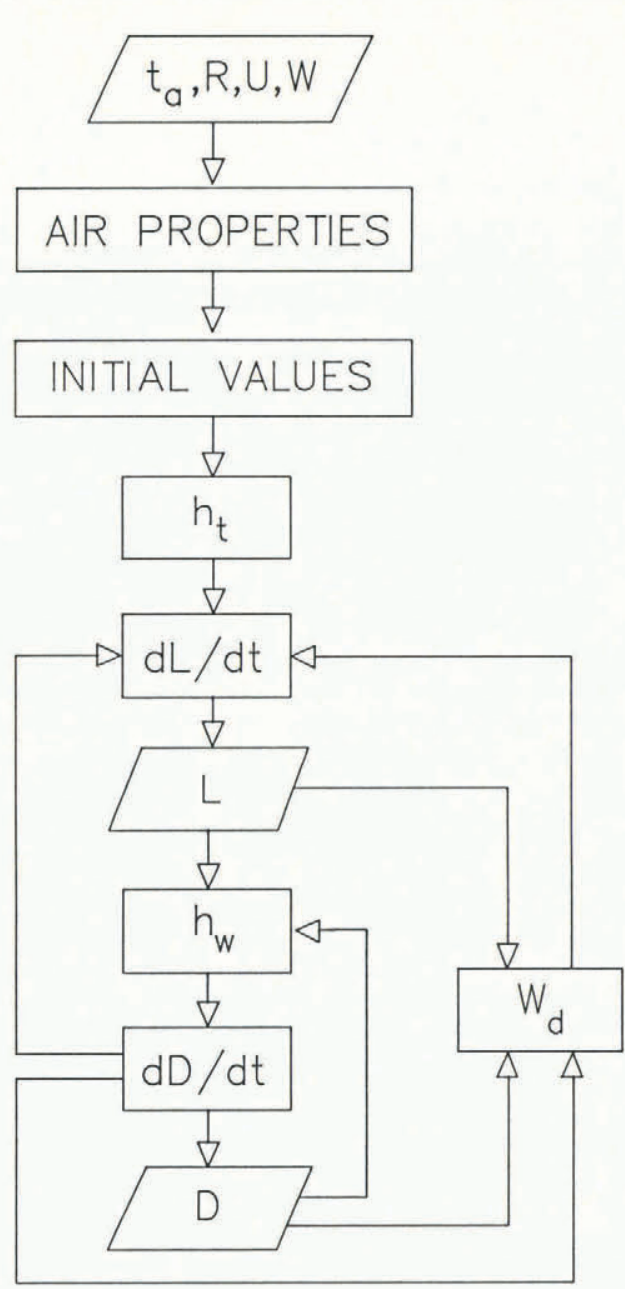

Fig. 2. Simplified block diagram of the icicle growth model.

sufficient for the icicle to elongate. This result is contrary to what one might intuitively expect, but it is in accordance with data from laboratory tests (Maeno and Takahashi, 1984[a]). As mentioned in section 3.1, the explanation of decreasing elongation rate with increasing water supply is the warming caused by drip water as the pendant drop leaves the tip more supercooled than what it is when it reaches the tip. The very small effect of $W_{0}$ on the growth rate of icicle width also agrees with observations by Maeno and Takahashi (1984[a]). That there is any noticeable effect of $W_{0}$ on $\mathrm{d} D / \mathrm{d} t$ in Figure 3 is because icicle length indirectly affects $\mathrm{d} D / \mathrm{d} t$ through the heattransfer coefficient (Appendix B).

The effect of wind on the growth of icicles is significant as shown in Figure 4. The air flow on the icicle surface changes from natural to forced at very low wind speeds (of the order of $0.05-0.5 \mathrm{~m} \mathrm{~s}^{-1}$ depending on air temperature and icicle dimensions), resulting in much more effective heat transfer and icing. At high wind speeds, long icicles can, however, seldom grow, because the water flowing on the icicle walls freezes before it reaches the icicle tip. In an extreme situation, this results in ice growth only at the root of the icicle and produces an ice accretion that is more like a cover of ice on the supporting structure than an icicle. The model results, therefore, indicate that long icicles grow only when there is almost no wind or when the water supply is very high (e.g. spray icing).

The effect of air temperature, $t_{\mathrm{a}}$, on icicle growth is such that both $\mathrm{d} L / \mathrm{d} t$ and $\mathrm{d} D / \mathrm{d} t$ depend linearly on $t_{\mathrm{a}}$. The effect of the relative humidity of air is much smaller than that of $t_{\mathrm{a}}$, but it is significant close to the freezing point. The effect of long-wave radiation on the model results is small. In Nature, however, the Sun's short-wave radiation under clear skies may heat the icicle walls and reduce $\mathrm{d} D / \mathrm{d} t$. 


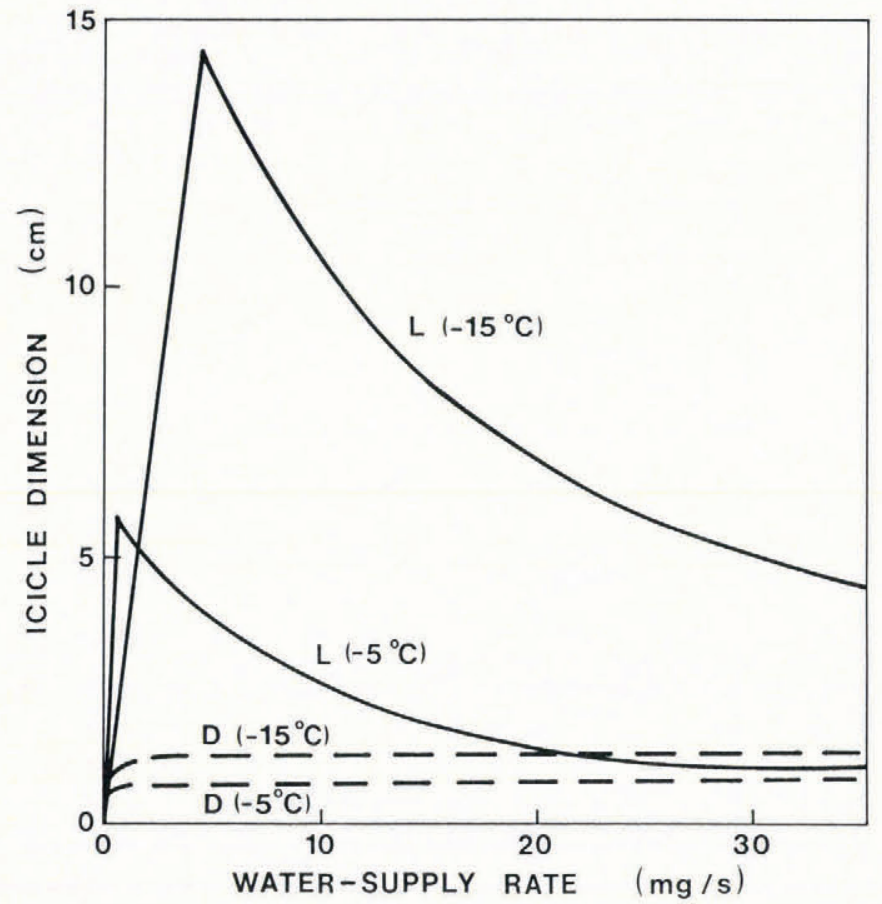

Fig. 3. Examples of model predictions of the icicle length $L$ and icicle width $D$ at two air temperatures and various water-supply rates. Air humidity of $80 \%$ and no wind are assumed. The values of $L$ and $D$ are the dimensions after $1 \mathrm{~h}$ of icicle growth.

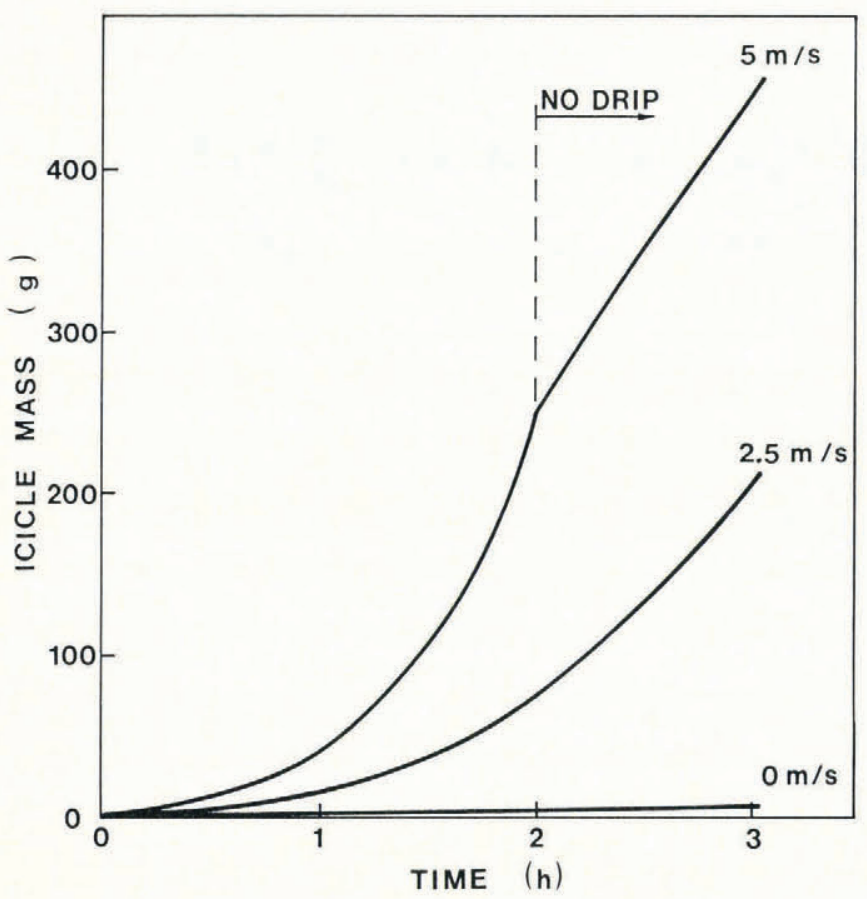

Fig. 4. Examples of model simulations of the icicle mass at various wind speeds. Air temperature of $-5^{\circ} \mathrm{C}$, humidity of $80 \%$, and water-supply rate of $50 \mathrm{mg} / \mathrm{s}$ are assumed.

Model simulations point out that the growth rate of and icicle is time-dependent. The elongation rate increases with time under fixed atmospheric conditions and water-supply rate. This is mainly due to the decreasing drip rate as more of the supply water is frozen on the walls the bigger the icicle. The growth rate in width slowly decreases with time mainly because the heat-transfer coefficient decreases with increasing icicle diameter. Under fixed conditions, the growth rate of icicle mass considerably increases with time, until the icicle grows so big that there is no drip and no growth in length. By that time all the supply water is collected by the icicle, and the mass-growth rate is a constant.

The model suggests no upper limit for the size of an icicle if conditions for its continuous growth prevail. Under natural conditions there are, however, several factors that limit the icicle size. If the water-supply rate, $W_{0}$, is high, the icicle initially grows very slowly and is unlikely to grow big. On the other hand, if $W_{0}$ is low, then the icicle soon ceases to elongate due to no flow to the icicle tip. Really big icicles can, therefore, form only under conditions in which the water-supply rate is at first small and continuously increases.

Other factors that may, under some conditions, limit the size of an icicle are the adhesion of ice to the substrate at the icicle root and the strength of the icicle in tension. Since the temperature of the supply water for the icicle is close to $0^{\circ} \mathrm{C}$, it tends to warm the root of the icicle and the supporting substrate. Close to $0^{\circ} \mathrm{C}$, the adhesion strength of ice and the structural strength of the icicle are quite low which may result in break-up when the icicle grows very heavy.

The mechanism of icicle growth presented in this paper is significantly different from the one proposed by Laudise and Barns (1979). It has not only been suggested in this paper that icicles elongate as hollow thin-walled tubes but it has been shown that icicles cannot form by any other means. The growth mechanisms proposed are in accordance with the observed structure of growing icicles (Geer, 1981; Maeno and Takahashi, 1984[a])

The laboratory experiments carried out by Maeno and Takahashi (1984[a]) make it possible to verify quantitatively the present model. These experiments were made in a cold room under calm conditions, varying the air temperature between $-4.9^{\circ}$ and $-20.3^{\circ} \mathrm{C}$, and water-supply rate between 4 and $30 \mathrm{mg} / \mathrm{s}$. The test duration was between 2 and $5 \mathrm{~h}$. The relative humidity and exact test duration were not reported by Maeno and Takahashi (1984[a]). In the model simulations, a relative humidity of $80 \%$ was assumed and the test duration was estimated from the figures by Maeno and Takahashi (1984[a]). Measured and modelled growth rates of icicle length are compared in Figure 5. A corresponding comparison for the growth rate in width is presented in Figure 6.

The comparisons in Figures 5 and 6 show very good agreement between model predictions and observations. The linear correlation coefficient is 0.96 for $\mathrm{d} L / \mathrm{d} t$ and 0.95 for $\mathrm{d} D / \mathrm{d} t$. Considerable success in predicting $\mathrm{d} D / \mathrm{d} t$ was expected, since modelling of ice growth on icicle walls is fairly straightforward and the theory for wet-growth icing has previously been well verified (Gates and others, 1986).

That the model successfully predicts $\mathrm{d} L / \mathrm{d} t$ is more remarkable. It indicates not only that the proposed elongation mechanism is correct but also that the assumed values of the model parameters are sufficiently accurate. It is particularly noteworthy that the assumption of the initial thickness of the downward-growing ice tube being a constant at a width of a single dendritic cell results in good agreement with observed icicle growth.

The data in Figures 5 and 6 show that the model can readily be used in predicting icicle growth over a large range of air temperature and water-supply rate. At present there are no data to verify the model under windy conditions. The growth mechanisms are, however, likely to be the same, so that there is no particular reason to expect worse model performance under windy than under calm conditions. Nevertheless, the model parameters may require some modification at high wind speeds due to icicle bending (see Maeno and Takahashi, 1984[b]) and a change in the shape of the vertical cross-section of the icicle, and possibly in the mean size of the pendant drop.

When applying the model in the marine environment one should also note that salt in the water affects the heat balance of an icing surface (Makkonen, 1987). Sea spray impinging directly on the icicle walls may also alter the heat balance. Furthermore, salinity affects the viscosity of water and may thereby change the size of the pendant drop from the one assumed in the model for fresh water. The importance of these effects on icicle growth should be studied. 


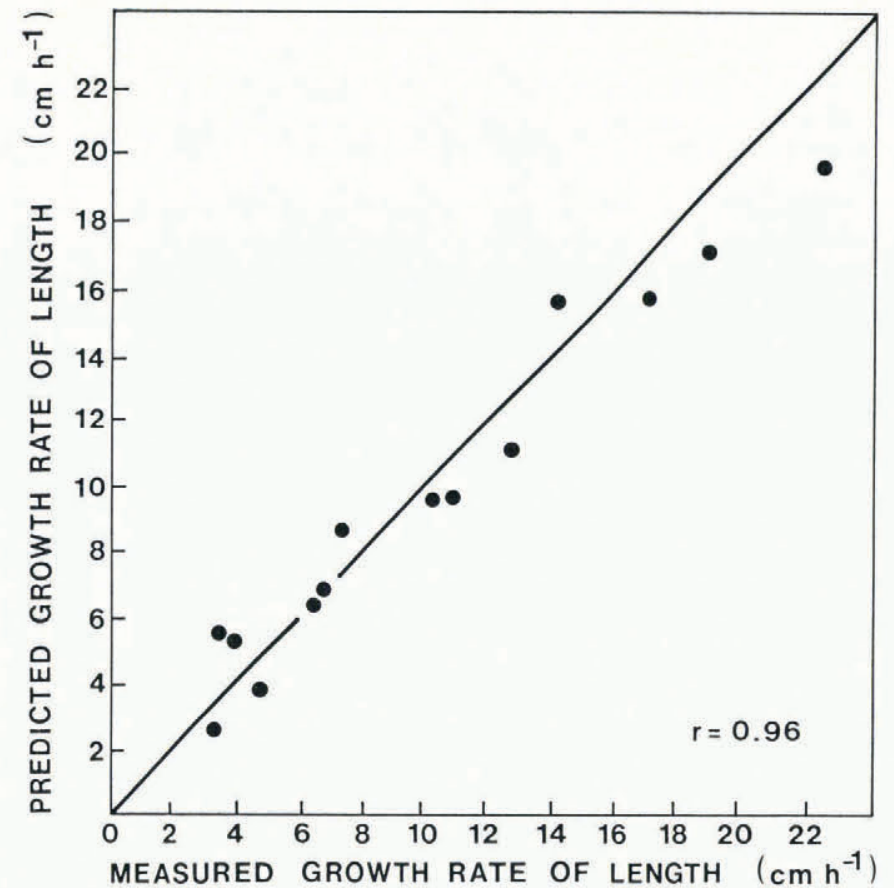

Fig. 5. Growth rate of icicle length as predicted by the theory versus the growth rate measured by Maeno and Takahashi (1984[a]).

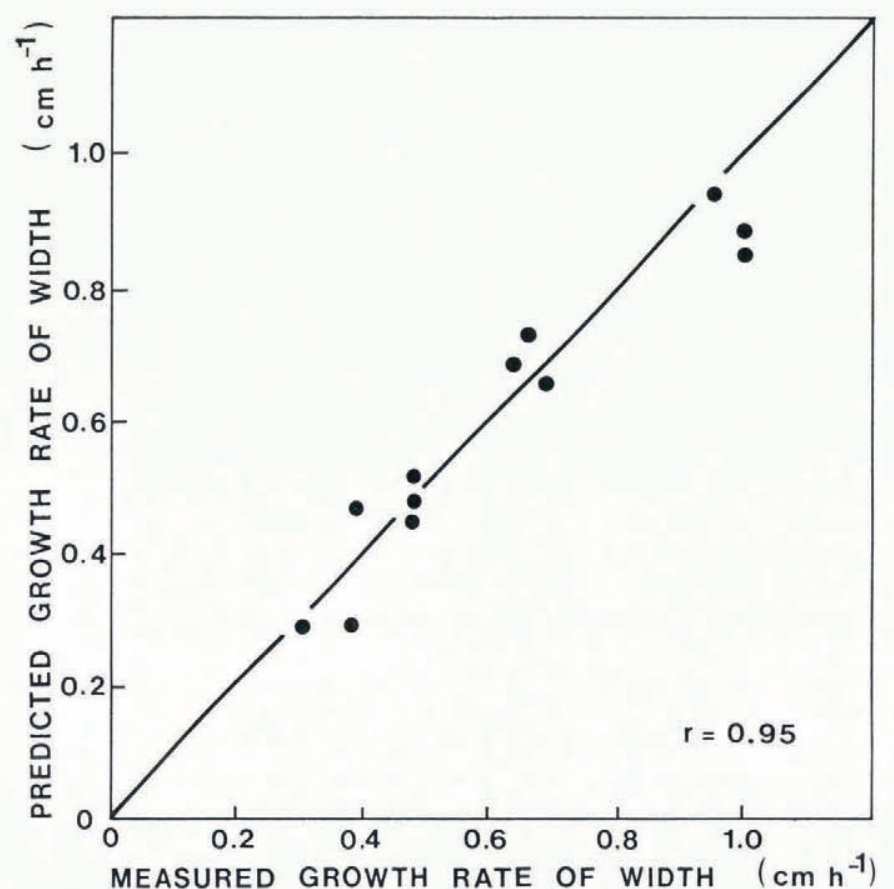

Fig. 6. Growth rate of icicle width as predicted by the theory versus the growth rate measured by Maeno and Takahashi (1984[a]).

\section{ACKNOWLEDGEMENTS}

I wish to thank Dr E.P. Lozowski and Dr C.A. Knight for their comments on the manuscript. This work was supported financially by the Finnish Broadcasting Co., Imatran Voima Co., and Finnish Post and Telecommunications Administration.

\section{REFERENCES}

Burt, S.D. 1982. The curious case of the horizontal icicles. Meteorological Magazine, 111(1320), 183-84.

Gates, E.M., Narten, R., Lozowski, E.P., and Makkonen, L. 1986. Marine icing and spongy ice. In International Association for Hydraulic Research. 8th International Symposium on Ice, Iowa City, August 18-22, 1986. Vol. 2. Iowa City, IA, University of Iowa. Institute of Hydraulic Research, 153-63.

Geer, I.W. 1981. The not-so-ordinary icicle. Weatherwise, 34(6), 257-59.

Harrison, J.D., and Tiller, A. 1963. Controlled freezing of water. In Kingery, W.D., ed. Ice and snow; properties, processes, and applications. Cambridge, MA, M.I.T. Press, 215-25.

Hatakeyama, H., and Nemoto, S. 1958. A note on the formation of horizontal stripes on icicles. Geophysical Magazine, 28(4), 477-82.

Hillig, W.B., and Turnbull, D. 1956. Theory of crystal growth in undercooled pure liquids. Journal of Chemistry and Physics, 24(4), 914.

Incropera, F.P., and DeWitt, D.P. 1985. Introduction to heat transfer. New York, Wiley \& Sons.

Knight, C.A. 1968. On the mechanism of spongy hailstone growth. Journal of the Atmospheric Sciences, 25(3), 440-44.

Knight, C.A. 1980. Icicles as crystallization phenomena. Journal of Crystal Growth, 49, 193-98.

Knudsen, J.G., and Katz, D.L. 1958. Fluid dynamics and heat transfer. New York, McGraw-Hill.

Laudise, R.A., and Barns, R.L. 1979. Are icicles single crystals? Journal of Crystal Growth, 46, 379-86.

Lenggenhager, K. 1978. Über wellige, stumpfe, glatte und spitze Eiszapfen. 1. Wellige und stumpfe Eiszapfen Zeitschrift für Meteorologie, 28(5), 292-97.

Lesins, G.B., List, R., and Joe, P.I. 1980. Ice accretions. Part I: Testing of new atmospheric icing concepts. Journal de Recherches Atmosphériques, 14(3-4), 347-56.

Maeno, N., and Takahashi, T. 1984[a]. Studies on icicles. I General aspects of the structure and growth of an icicle. Low Temperature Science, Ser. A, 43, 125-38. [In Japanese.]

Maeno, N., and Takahashi, T. 1984[b]. Studies on icicles. II. Wave-forms, spikes and bent icicles. Low Temperature Science, Ser. A, 43, 139-47. [In Japanese.]

Makkonen, L. 1984. Modeling of ice accretion on wires. Journal of Climate and Applied Meteorology, 23(6), 929-39.

Makkonen, L. 1987. Salinity and growth rate of ice formed by sea spray. Cold Regions Science and Technology, 14(2), 163-71.

Reesman, A.L. 1973. Icicles: a guide to the quality and movement of groundwater. American Geological Society. Abstracts, 5(7), 777.

Schlichting, H. 1979. Boundary-layer theory. New York, McGraw-Hill.

Shinojima, K. 1973. Icicle formation in tunnels under train running. Quarterly Report of the Railway Technical Research Institute (Tokyo), 41(3), 121-22.

Sparrow, E.M., and Stretton, A.J. 1985. Natural convection from variously oriented cubes and from other bodies of unity aspect ratio. International Journal of Heat and Mass Transfer, 28(4), 741-52.

\section{APPENDIX A}

\section{HEAT-TRANSFER COEFFICIENT FOR THE TIP OF THE ICICLE}

The heat-transfer coefficient $h_{\mathrm{t}}$ in Equation (16) can be written in terms of the Nusselt number $\mathrm{Nu}$ as

$$
h_{\mathrm{t}}=\frac{k_{\mathrm{a}} \mathrm{Nu}_{\mathrm{t}}}{d}
$$

where $k_{\mathrm{a}}$ is the thermal conductivity of air. 
For free convection, it is assumed in the model that the Nusselt number for the tip of the icicle, i.e. the mean Nusselt number of the pendant drop, is equal to that of a sphere. The following parameterization is used (Sparrow and Stretton, 1985):

$$
\mathrm{Nu}{ }_{\mathrm{t}}^{\mathrm{N}}=1.83+0.398 \mathrm{Gr}_{\mathrm{t}}^{0.252} .
$$

Here $\mathrm{Gr}_{\mathrm{t}}$ is the Grashof number

$$
\mathrm{Gr}_{\mathrm{t}}=\frac{g d^{3}\left(0^{\circ} \mathrm{C}-t_{\mathrm{a}}\right)}{v^{2}\left(t_{\mathrm{a}}+273.15^{\circ} \mathrm{C}\right)}
$$

where $g$ is the acceleration of gravity and $v$ is the kinematic viscosity of air.

For forced convection, the equation of Knudsen and Katz (1958) is used

$$
\mathrm{Nu}_{\mathrm{t}}^{\mathrm{F}}=2.0+0.538 \mathrm{Re}_{\mathrm{t}}^{0.5}
$$

Here $\mathrm{Re}_{\mathrm{t}}$ is the Reynolds number

$$
\mathrm{Re}_{\mathrm{t}}=\frac{U d}{\mathrm{u}}
$$

where $U$ is the wind speed.

The model calculates both $\mathrm{Nu}_{t}^{N}$ and $\mathrm{Nu}_{t}^{\mathrm{F}}$, and the one that is higher is set to be the Nusselt number of the tip of the icicle in Equation (A1).

\section{APPENDIX B}

HEAT-TRANSFER COEFFICIENT FOR THE WALLS OF THE ICICLE

The mean heat-transfer coefficient $h_{\mathrm{w}}$ in Equation (22) for the walls of the icicle is

$$
h_{\mathrm{w}}=\frac{k_{\mathrm{a}} \mathrm{Nu}_{\mathrm{w}}}{L}
$$

where $L$ is the length of the icicle.

For free convection, the Nusselt number of the walls is first calculated from (cf. Schlichting, 1979)

$$
\mathrm{Nu}_{\mathrm{w}, \mathrm{L}}^{\mathrm{N}}=0.478 \mathrm{Gr}^{0.25}
$$

and then a correction for curvature is made using the equation (Knudsen and Katz, 1958)

$$
\mathrm{Nu}_{\mathrm{w}}^{\mathrm{N}}=\frac{0.9 S N \mathrm{u}_{\mathrm{w}, \mathrm{L}}^{\mathrm{N}}}{\ln (1+0.9 S)}
$$

where

$$
S=\frac{2 L}{D N u_{\mathrm{w}, \mathrm{L}}^{\mathrm{N}}} .
$$

For forced convection, Hilbert's equations (cf. Incropera and DeWitt, 1985) for a smooth cylinder are used

$$
\begin{aligned}
& N u_{w}^{F}=0.881 \mathrm{Re}_{\mathrm{w}}{ }^{0.330} \text { for } 0.4<\mathrm{Re}_{\mathrm{w}} \leqslant 4 \\
& N u_{\mathrm{w}}^{\mathrm{F}}=0.811 \mathrm{Re}_{\mathrm{w}}{ }^{0.385} \text { for } 4<\mathrm{Re}_{\mathrm{w}} \leqslant 40 \\
& \mathrm{Nu}_{\mathrm{w}}^{\mathrm{F}}=0.608 \mathrm{Re}_{\mathrm{w}}{ }^{0.466} \text { for } 40<\mathrm{Re}_{\mathrm{w}} \leqslant 4000 \\
& N u_{\mathrm{w}}^{\mathrm{F}}=0.172 \mathrm{Re}_{\mathrm{w}}{ }^{0.618} \text { for } 4 \times 10^{3}<\mathrm{Re}_{\mathrm{w}} \leqslant 4 \times 10^{4} \\
& N u_{\mathrm{w}}^{\mathrm{F}}=0.024 \mathrm{Re}_{\mathrm{w}}{ }^{0.805} \text { for } 4 \times 10^{4}<\mathrm{Re}_{\mathrm{w}} \leqslant 4 \times 10^{5}
\end{aligned}
$$

where $\operatorname{Re}_{w}$ is the cylinder Reynolds number

$$
\operatorname{Re}_{\mathrm{w}}=\frac{U D}{v} .
$$

The higher one of the Nusselt numbers $\mathrm{Nu}_{\mathrm{w}}^{\mathrm{N}}$ and $\mathrm{Nu}_{\mathrm{W}}^{\mathrm{F}}$ is used in Equation (B1) to calculate the heat-transfer coefficient of the icicle walls. 